\title{
Disaggregation of Future Regional Climate Model Data to Generate Future Rainfall Intensity-Duration-Frequency Curves to Assess Climate Change Impacts
}

\author{
Hüsamettin Tayşi ${ }^{1}$ and Mehmet Ozger ${ }^{2}$ \\ ${ }^{1}$ Gebze Technical University \\ ${ }^{2}$ Istanbul Technical University
}

March 18, 2021

\begin{abstract}
Heavy increase in urbanization, industrialization and population is causing an increase in emissions of greenhouse gases (GHG) and this causes variations in atmosphere. Climate change causes extreme rainfall events and these events are expected to be enhanced in the future. Since flooding is influencing urban areas, controlling and management of flooding is a major necessity. Intensity-Duration-Frequency (IDF) curves play a huge role in representing rainfall characteristics by linking intensity, duration, and frequency of rainfall. Analysing short-duration rainfall is crucial for urban areas due to fast responses of drainage systems against heavy rainfall events. IDF curves were generated via the Gumbel method for rainfalls from 5-min to 24-h in this study. However, providing short-duration rainfall data is challenging due to the low capacity, costs and geographic conditions. Therefore, the HYETOS disaggregation model was applied to obtain sub-hourly data. IDF curves are stationary since they only consider historical events. However, IDF curves must be non-stationary and time varying based on preparation for upcoming extreme events. This study aims to generate IDF curves under climate change scenarios. The Regional Climate Model (RCM) HadGEM2-ES generated under Representative Concentration Pathways (RCP) 4.5 and 8.5 scenarios and was used in the study to represent future rainfalls. Future daily rainfalls were disaggregated into sub-hourly using disaggregation parameters of corresponding station's historical rainfall data since it is impossible to estimate parameters when hourly data is not available. With this new approach, future daily rainfall data is disaggregated into 5-min data by complying with historical rainfall patterns rather than complying with randomly selected rainfall characteristics. The study concluded that future rainfall intensities increases compared to historical IDF curves. RCP8.5 scenarios have higher rainfall intensities for all return periods compared to RCP4.5 scenarios for all stations except a station. In addition, the accuracy of the selected disaggregation model was verified.
\end{abstract}

\section{Disaggregation of Future Regional Climate Model Data to Generate Future Rainfall Intensity- Duration-Frequency Curves to Assess Climate Change Impacts}

Disaggregation of Future Rainfalls to Generate IDF Curves

Hüsamettin Tayşi ${ }^{1}$, Mehmet Özger ${ }^{2}$

${ }^{1}$ Faculty of Engineering, Department of Civil Engineering, Gebze Technical University, Gebze, 41400 Kocaeli, Turkey

${ }^{2}$ Faculty of Civil Engineering, Department of Hydraulics and Water Resources Engineering, Istanbul Technical University, Sariyer, 34467 Istanbul, Turkey

Corresponding Author : Hüsamettin Tayşi 
Faculty of Engineering, Department of Civil Engineering, Gebze Technical University, Gebze, 41400 Kocaeli, Turkey

e-mail: h.taysi@gtu.edu.tr

\section{ACKNOWLEDGEMENTS}

This study was supported by The Scientific and Technological Research Council of Turkey (TUBITAK) 2210-C Program (The grant number is 1649B021900038). I acknowledge TUBITAK for their contributions and financial support. I am also thankful to the Turkish State Meteorological Service (TSMS) for providing the required data in the study.

\section{Hosted file}

Main Text.pdf available at https://authorea.com/users/402290/articles/514147-disaggregationof-future-regional-climate-model-data-to-generate-future-rainfall-intensity-durationfrequency-curves-to-assess-climate-change-impacts

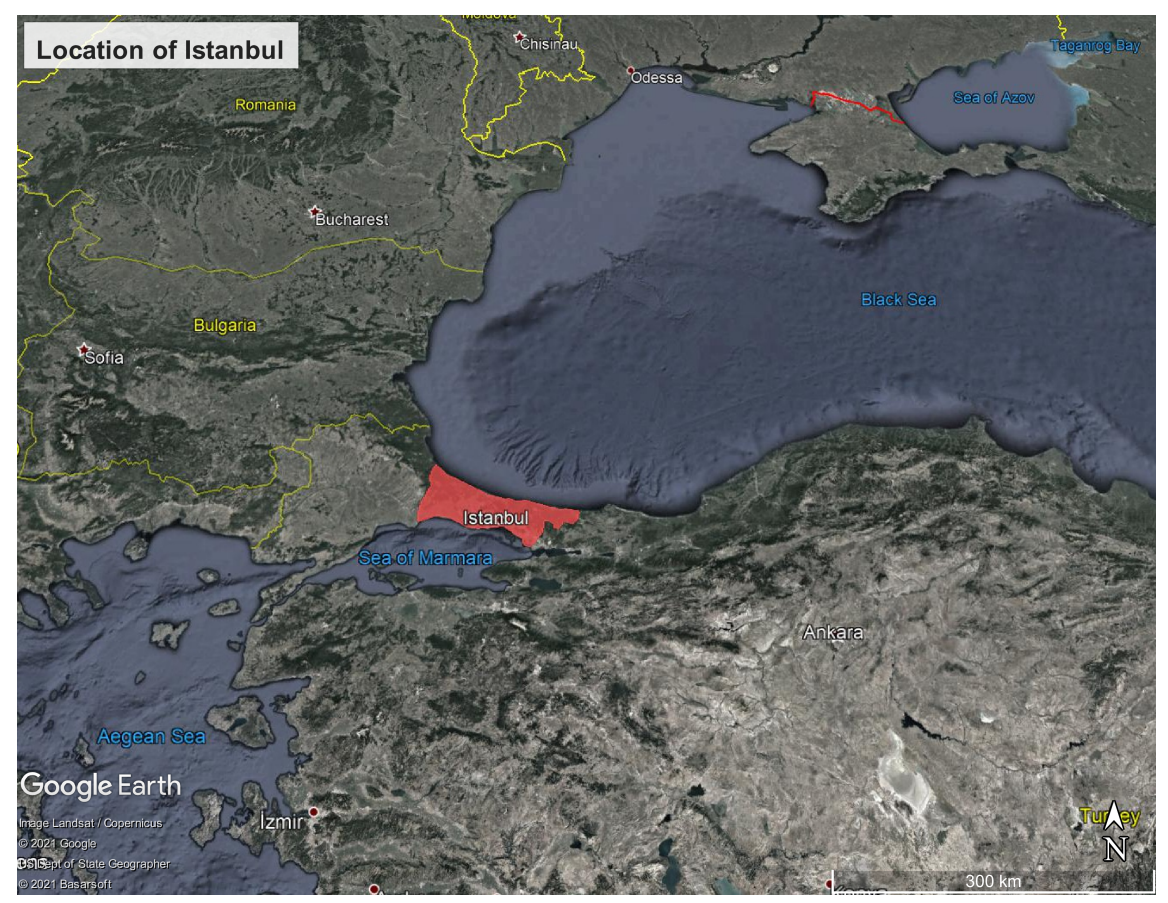



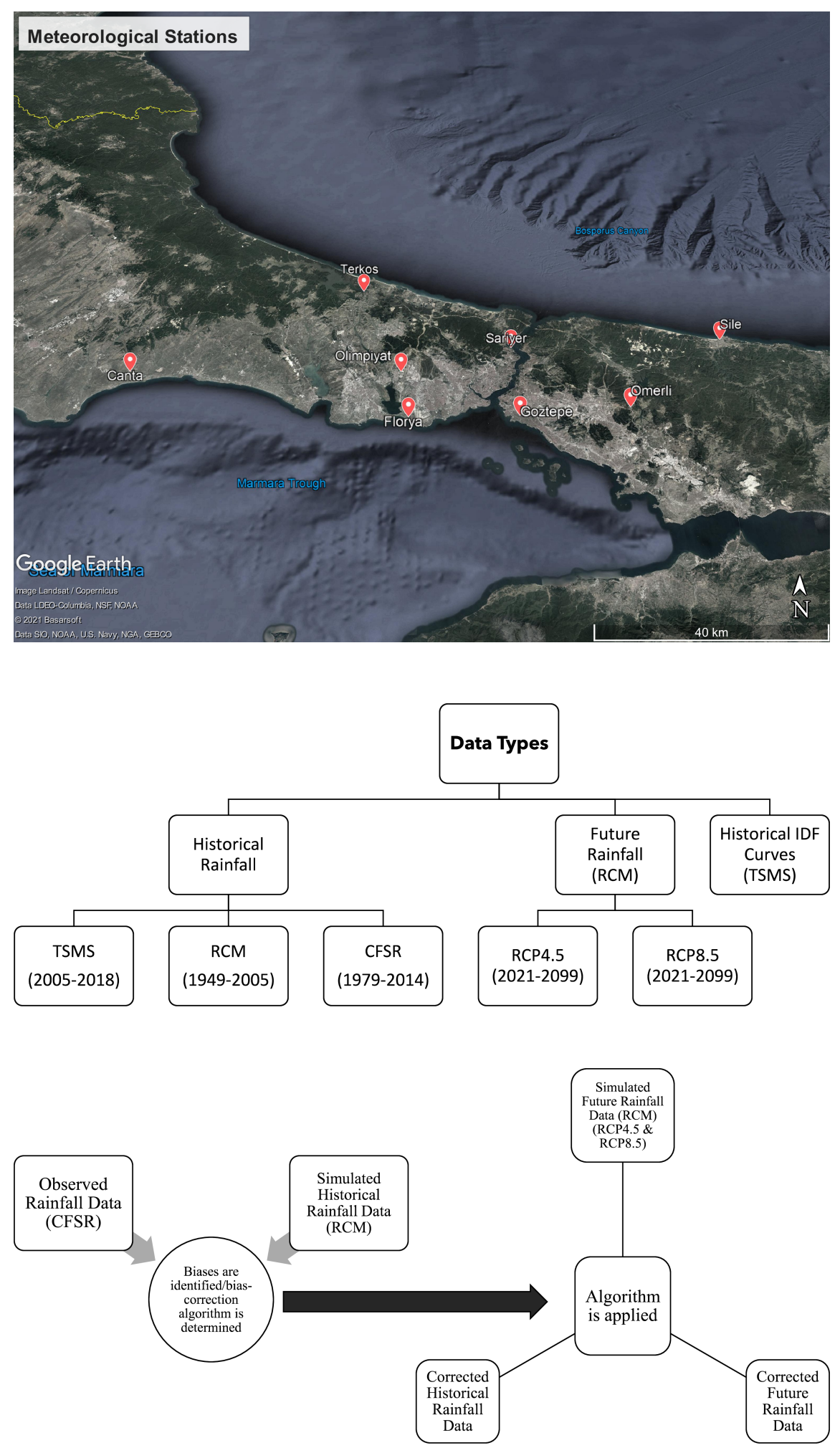

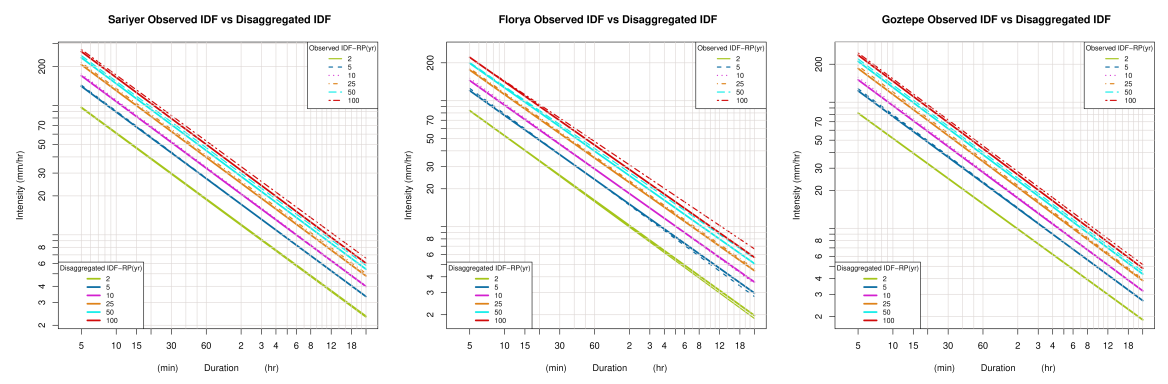

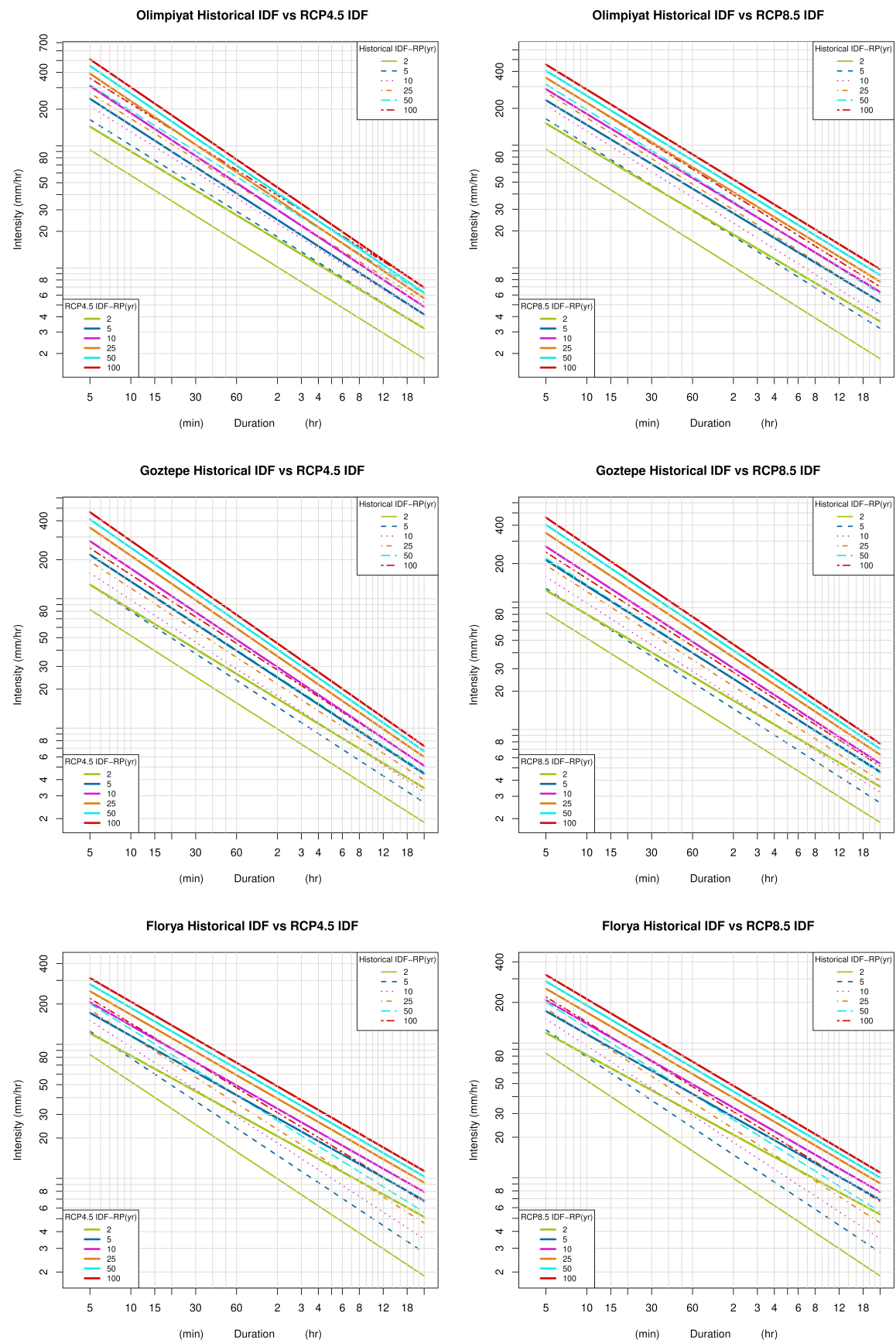

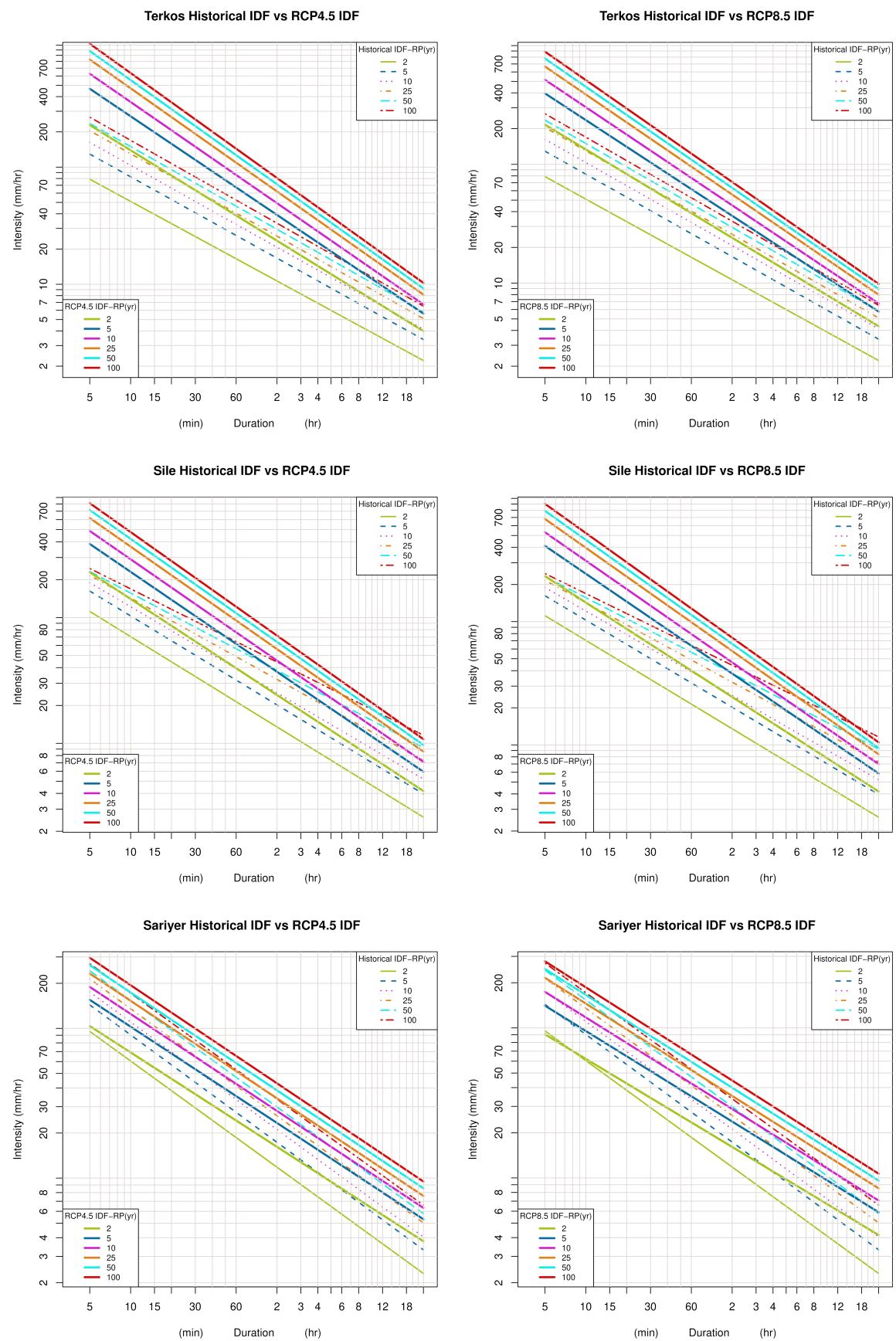

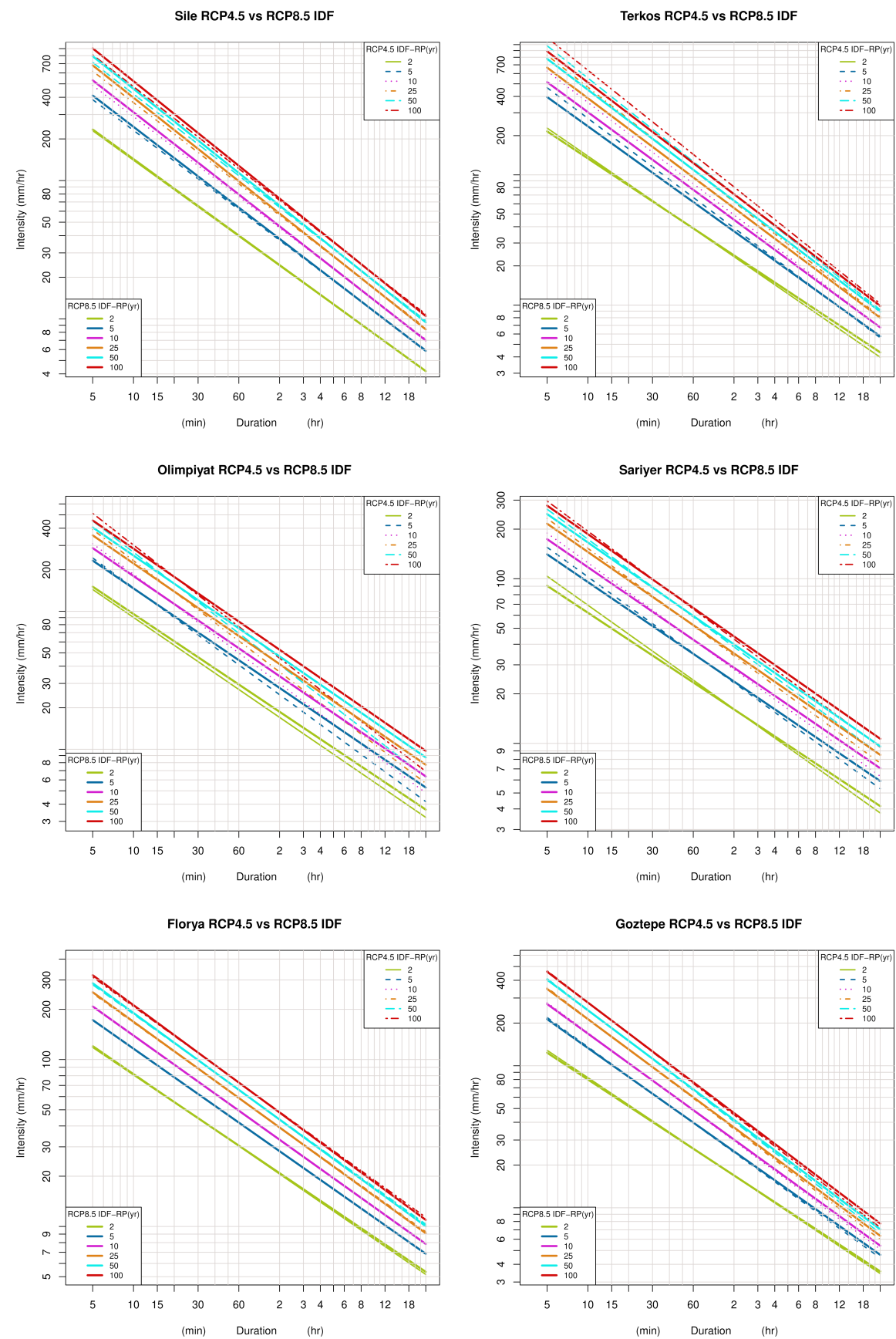